\title{
Examination of the Heat Transfer Model in Gas-Liquid-Solid Three Phases in Presence of Gas Hydrate Particle
}

\author{
Ryosuke EzUrE*, Yusuke TAKAHASHI, Shun TAKANo, Hiroyuki Komatsu, Kazuaki Yamagiwa, and Hideo TAJIMA* \\ Graduate School of Science and Technology, Niigata University, 2-8050 Ikarashi, Niigata 950-2181, Japan
}

\begin{abstract}
Hydrate-based gas separation is often investigated using batch or semi-batch operations. To increase the throughput of the gas mixture without increasing the apparatus volume, it is preferable to perform a continuous operation of hydrate-based gas separation. Therefore, we proposed a flow-type apparatus for performing continuous formation with passing gaseous mixture and subsequently decomposition with passing gas hydrate particles. Characteristics of multiple fluid and heat and mass transfer of hydrate slurry are essential for the efficient operation of the apparatus. In this study, we focused on heat transfer characteristics in the presence of bubbles in water and surfactant solution. First, an apparent overall heat transfer coefficient under pressure during steady operation of the apparatus was calculated on a simple assumption. Next, to control the hydrate amount and position of hydrate-decomposition and hydrate-formation in the apparatus, we focused on the temperature profile of the inside fluid. A heat transfer model using heat balance of defining heat of hydrate-formation and heat transfer of agitation of fluid was made for hydrate-based gas separation apparatus. To evaluate the validity of the heat transfer model, a calculation value is compared with the experimental value.
\end{abstract}

\section{Introduction}

Gas hydrate is a non-stoichiometric crystal compound formed by the inclusion of gas molecules in the space of water molecules bound in a cage form by hydrogen bonding. Gas hydrate exists under low temperature and high pressure. There are many applied technologies of gas hydrate. In our laboratory, we are focusing on a hydrate-based gas separation in many applied technologies (Tajima et al., 2014). Hydrate-based gas separation is often investigated using batch or semibatch operations. To increase the throughput of the gas mixture without increasing the apparatus volume, it is preferable to perform a continuous operation of hydratebased gas separation. When gas hydrate formation for gas absorption and decomposition for gas stripping are carried out with a flow-type reactor, characteristics of multiple fluids (gas-liquid-solid phase) and heat and mass transfer are important information. However, there is little information about these characteristics yet. Therefore, we focused on heat transfer characteristics in the presence of bubbles and hydrate particles in water and surfactant solution. The aim of this study is to suggest a heat transfer model of hydrate slurry under the gas-liquid-solid three phases. Several heat transfer models by heat balances of the conditions as shown in Table1 were made and assessed based on assumptions for simplification. To evaluate the validity of the heat transfer model in the gas-liquid two phases, a calculation value was compared with the experimental value.

Table 1. Condition of the heat transfer model

\begin{tabular}{cc}
\hline $\begin{array}{c}\text { Back } \\
\text { mixing }\end{array}$ & $\begin{array}{c}\text { Heat of } \\
\text { reaction }\end{array}$ \\
\hline No & No \\
No & Yes \\
Yes & No \\
Yes & Yes \\
\hline
\end{tabular}

\section{Experimental Method}

\subsection{Experimental method}

\subsubsection{Experimental apparatus}

We combined a hydrate-decomposition part with a hydrate-formation apparatus (Tajima et al., 2014) for continuous operation as shown in Figure 1. A staticmixer was set up in the hydrate-formation reactor because gas came in contact with liquid thoroughly. $\mathrm{Pt}$ residence thermometers were equipped at the top and the bottom of the hydrate-formation and the hydratedecomposition parts respectively. To keep the apparatuses at a constant temperature, those apparatuses

* Corresponding author: f18b029f@mail.cc.niigata-u.ac.jp (R. Ezure), h_tajima@eng.niigata-u.ac.jp (H. Tajima) 
were set up in separate low-temperature thermostats in which the air of forced convection in low-temperature thermostats cool those apparatuses.

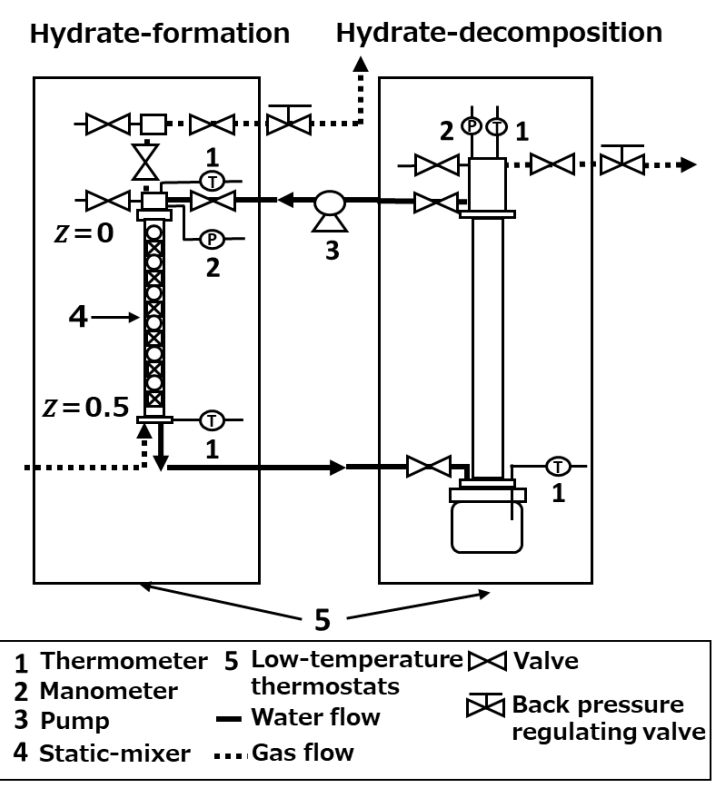

Figure 1. Experimental apparatus

\subsubsection{Experimental operation}

In order to produce gas hydrate, we used HCFC-22 (chlorodifluoromethane, R22) and nitrogen as test gases and ion-exchanged water. Water looped in the apparatus by using a pump. When water was cooled in the apparatus, the experimental temperature was set to 276 $\mathrm{K}$ or $278 \mathrm{~K}$ at the hydrate-formation side and $286 \mathrm{~K}$ at the hydrate-decomposition side. Because the temperature in the center of the reactor equipped a static mixer kept the temperature of hydrate-formation or decomposition. Injected gas was contacted to water countercurrently. Experimental pressure in the apparatuses was set at $0.3 \mathrm{MPa}$ (An equilibrium temperature of HCFC-22 hydrate is $282.2 \mathrm{~K}$ at $0.291 \mathrm{MPa}$ ) (Javanmardi et al., 2004). To form hydrate slurry readily, the SDS solution (100ppm) was also tested instead of pure water. We measured the temperature at a steady state in the apparatuses in each condition.

\subsection{Analysis method}

To establish a heat transfer model fitted the hydrate formation apparatus, we took a step-by-step approach for the heat balance.

\subsubsection{Estimation of overall heat transfer coefficient}

To decide the overall heat transfer coefficient of the hydrate formation (static mixing) part, we measured the temperature at a steady state in the apparatuses with the water phase only. Temperature distribution in the apparatus was calculated by using forced convection heat transfer equation and heat balance. The average velocity of an air-cooling in the thermostats was estimated as a calculation value was equal to the experimental value. The overall heat transfer coefficient $U$ was calculated using the following Equations (1)-(6).

$$
\begin{aligned}
\operatorname{Re} & =\frac{D \rho_{\text {Air }} u}{\mu} \\
\operatorname{Pr} & =\frac{C_{\text {Air }} \mu}{\lambda} \\
\mathrm{Nu} & =0.689 \operatorname{Re}^{0.466} \operatorname{Pr}^{\frac{1}{3}} \\
\mathrm{~h} & =\frac{N u \times \lambda}{D} \\
\mathrm{U} & =\frac{1}{\frac{\delta}{\lambda}+\frac{1}{h}}
\end{aligned}
$$

$$
\rho_{L} C_{P L} F_{L} \frac{d T_{z}}{d Z}+\pi D U\left(T_{Z}-T_{F}\right)=0
$$

- $C_{A i r}:$ specific heat of air $[\mathrm{kJ} /(\mathrm{K} \cdot \mathrm{kg})]$

- $C_{P L}:$ specific heat of pure water $[\mathrm{J} /(\mathrm{K} \cdot \mathrm{kg})]$

$\cdot D$ : diameter of the reactor apparatus $[\mathrm{m}]$

- $F_{L}$ : volumetric flow of pure water $\left[\mathrm{m}^{3} / \mathrm{s}\right]$

$\cdot h:$ heat transfer coefficient $\left[\mathrm{W} /\left(\mathrm{m}^{2} \cdot \mathrm{K}\right)\right]$

- $N u$ : Nusselt number [-]

- Pr : Prandtl number [-]

$\cdot$ Re : Reynolds number [-]

- $T_{Z}$ : temperature in the reactor at a certain position [K]

- $T_{F}$ : temperature setting of the low-temperature thermostats [K]

- $U$ : overall heat transfer coefficient $\left[\mathrm{W} /\left(\mathrm{m}^{2} \cdot \mathrm{K}\right)\right]$

$\cdot u$ : average velocity of the air-cooling $[\mathrm{m} / \mathrm{s}]$

$\cdot \delta:$ thickness of the circular tube made glass [m]

$\cdot \lambda:$ thermal conductivity of air $[\mathrm{W} /(\mathrm{m} \cdot \mathrm{s})]$

$\cdot \mu$ : viscosity of air $[\mathrm{Pa} \cdot \mathrm{s}]$

- $\rho_{\text {Air }}$ : density of air $\left[\mathrm{kg} / \mathrm{m}^{3}\right]$

- $\rho_{L}:$ density of water $\left[\mathrm{kg} / \mathrm{m}^{3}\right]$

\subsubsection{The heat transfer model without the back mixing and heat of formation of hydrate}

Figure 2 shows the image of the heat balance without the back mixing and heat of formation of hydrate. The heat balance was taken based on the following assumptions.

- The flow in the apparatus is the plug flow because a static-mixer is equipped in the apparatus.

- The thermal boundary layer inside the circular tube can be ignored. 


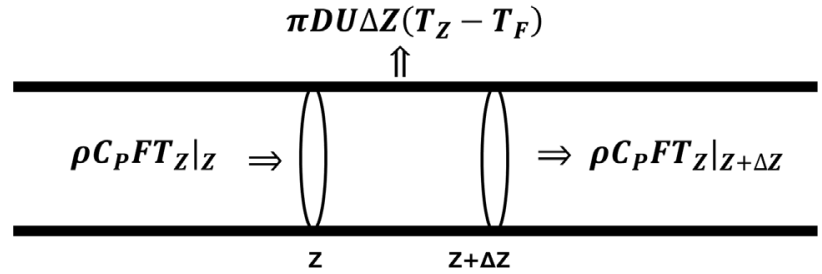

Figure 2. The image of the heat balance without the back mixing and heat of formation of hydrate

The heat balance equation is as follows under a steady state:

$$
\rho C_{P} F \frac{d T_{z}}{d Z}+\pi D U\left(T_{Z}-T_{F}\right)=0
$$

- $C_{P}$ : average specific heat of the fluid $[\mathrm{kJ} /(\mathrm{K} \cdot \mathrm{kg})]$

$\cdot F$ : average of the volumetric flow of the fluid $\left[\mathrm{m}^{3} / \mathrm{s}\right]$

$\cdot \rho$ : average density of the fluid $\left[\mathrm{kg} / \mathrm{m}^{3}\right]$

The overall heat transfer coefficient was calculated without the gas. Here, an average density of the fluid and an average specific heat of the fluid, an average of the volumetric flow of the fluid were calculated by the following Equations (8)-(10).

$$
\begin{gathered}
F=F_{G}+F_{L} \\
\rho=\rho_{G} \varepsilon_{G}+\rho_{L} \varepsilon_{L} \\
C_{P}=C_{P G} \varepsilon_{G}+C_{P L} \varepsilon_{L}
\end{gathered}
$$

- $C_{P G}:$ pecific heat of the gas $[\mathrm{J} /(\mathrm{K} \cdot \mathrm{kg})]$

$\cdot F_{G}$ : volumetric flow of the gas $\left[\mathrm{m}^{3} / \mathrm{s}\right]$

$\cdot \varepsilon_{G}:$ gas holdup[-]

$\cdot \varepsilon_{L}:$ liquid holdup [-]

- $\rho_{G}:$ density of the gas $\left[\mathrm{kg} / \mathrm{m}^{3}\right]$

\subsubsection{The heat transfer model with the heat of formation of hydrate}

Figure 3 shows the image of the heat balance with the heat of formation of hydrate. The heat balance was taken under the same assumptions as Section 2.2.2.

The heat balance equation is as follows under a steady state:

$$
\rho C_{P} F \frac{d T_{z}}{d Z}+\pi D U\left(T_{Z}-T_{F}\right)-\frac{1}{8} r H=0
$$

$\cdot H$ : enthalpy of the hydrate-decomposition $[\mathrm{J} / \mathrm{mol}]$ $\cdot r$ : hydrate formation rate per unit length $[\mathrm{mol} /(\mathrm{m} \cdot \mathrm{s})]$

This overall heat transfer coefficient was calculated without the gas. An average density of the fluid and an average specific heat of the fluid, an average of the volumetric flow of the fluid were calculated by the method similar to Section 2.2.2.

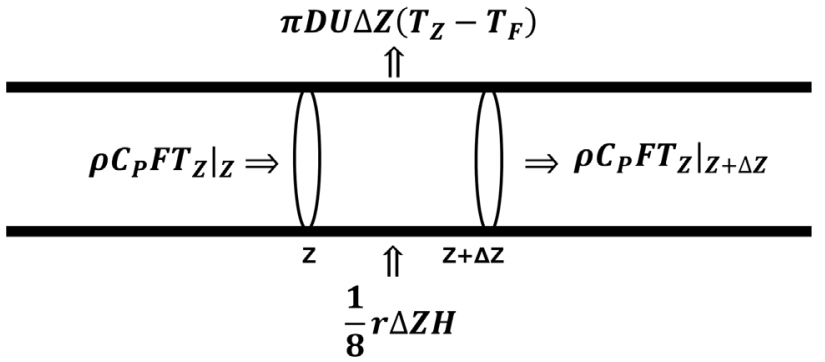

Figure 3. The image of the heat balance with the heat of formation of hydrate

\subsubsection{The heat transfer model with back mixing}

Figure 4 shows the image of the heat balance with the back mixing. The heat balance was taken based on the following assumption.

- The temperature distribution and the volumetric flow distribution in the apparatus are constant in the radial direction.

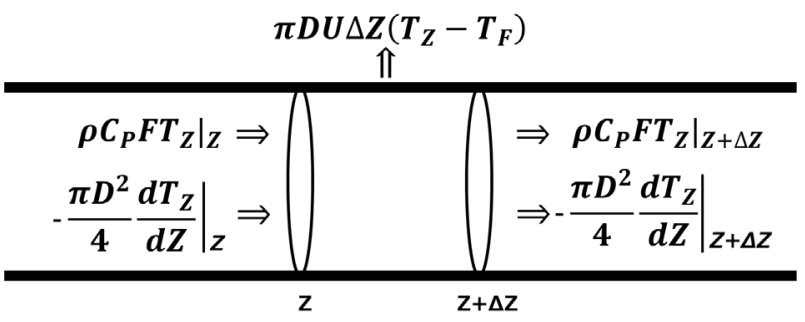

Figure 4. The image of the heat balance with the back mixing

The heat balance equation is as follows under a steady state (Muroyama et al., 1984):

$$
k_{e z} \frac{d^{2} T_{Z}}{d Z^{2}}-\frac{4 \rho C_{P} F}{D^{2} \pi} \frac{d T_{z}}{d Z}-\frac{4 U}{D}\left(T_{Z}-T_{F}\right)=0
$$

$\cdot k_{e z}$ : effective axial thermal conductivity $[\mathrm{W} /(\mathrm{m} \cdot \mathrm{K})]$

The overall heat transfer coefficient was calculated without the gas. An average density of the fluid and an average specific heat of the fluid, an average of the volumetric flow of the fluid were calculated by the method similar to Section 2.2.2.

An effective axial thermal conductivity was calculated by the following equation (Muroyama et al., 1978).

$$
k_{e z}=\rho_{L} C_{P L} \varepsilon_{L} E_{z L}+\rho_{S} C_{P S} \varepsilon_{S} E_{z S}
$$

- $C_{P L}:$ specific heat of pure water $[\mathrm{J} /(\mathrm{K} \cdot \mathrm{kg})]$

- $C_{P S}:$ specific heat of gas hydrate $[\mathrm{J} /(\mathrm{K} \cdot \mathrm{kg})]$

$\cdot E_{z L}$ : axial dispersion coefficient of liquid $\left[\mathrm{m}^{2} \cdot \mathrm{s}\right]$

$\cdot E_{z S}$ : axial dispersion coefficient of solid $\left[\mathrm{m}^{2} / \mathrm{s}\right]$

$\cdot \varepsilon_{L}:$ liquid holdup [-]

$\cdot \varepsilon_{S}:$ solid holdup [-]

- $\rho_{L}:$ density of pure water $\left[\mathrm{kg} / \mathrm{m}^{3}\right]$

- $\rho_{S}:$ density of the gas hydrate $\left[\mathrm{kg} / \mathrm{m}^{3}\right]$ 
When the gas velocity is high, $E_{z L}$ is equal to $E_{z S}$. Therefore, $k_{e z}$ was calculated in the condition of $E_{z L}=$ $E_{z S}$.

An axial dispersion coefficient of liquid was calculated by the following equation (Muroyama et al., 1978).

$$
P e=\left(V_{L} D / E_{z L}\right)=1.07 U_{L}^{0.738} U_{G}^{-0.167} D^{-0.583}
$$

$\cdot D$ : diameter of the reactor apparatus [cm]

- Pe : Peclet number [-]

- $U_{L}:$ superficial liquid flow rate $[\mathrm{cm} / \mathrm{s}]$

- $U_{G}:$ superficial gas flow rate $[\mathrm{cm} / \mathrm{s}]$

- $V_{L}:$ mean velocity of liquid $[\mathrm{cm} / \mathrm{s}]$

\subsubsection{The heat transfer model with the back mixing and heat of formation of hydrate}

Figure 5 shows the image of the heat balance with the back mixing and heat of formation of hydrate. The heat balance was taken under the same assumptions as Section 2.2.4.

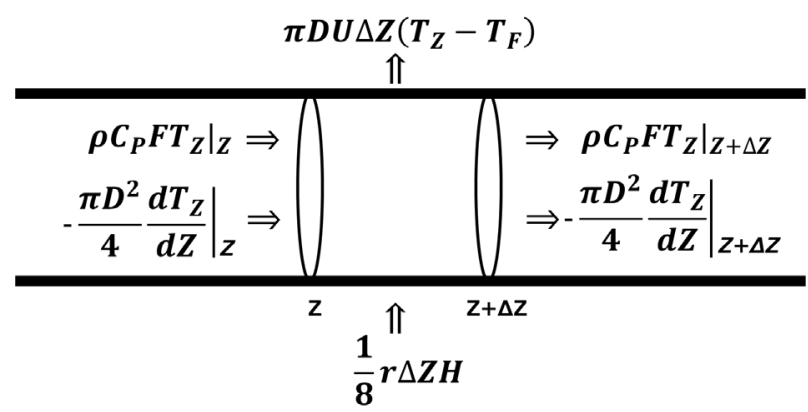

Figure 5. The image of the heat balance with the back mixing and heat of formation of hydrate

The heat balance equation is as follows under a steady state:

$$
k_{e z} \frac{d^{2} T_{Z}}{d Z^{2}}-\frac{4 \rho C_{P} F}{D^{2} \pi} \frac{d T_{z}}{d Z}-\frac{4 U}{D}\left(T_{Z}-T_{F}\right)+\frac{r H}{2 D^{2} \pi}=0
$$

The overall heat transfer coefficient was calculated without the gas. An average density of the fluid and an average specific heat of the fluid, an average of the volumetric flow of the fluid were calculated by the method similar to Section 2.2.2.

\section{Result and Discussion}

\subsection{Estimation of overall heat transfer coefficient}

When the calculation value from Equations (1)-(6) was equal to the experimental value, the average velocity of air-cooling $u$ was $2.68 \mathrm{~m} / \mathrm{s}$. This value is adequate as air- cooling velocity in a thermostatic chamber. Therefore, we used this value in this study.

\subsection{The temperature distribution in the reactor with the gas at atmospheric pressure}

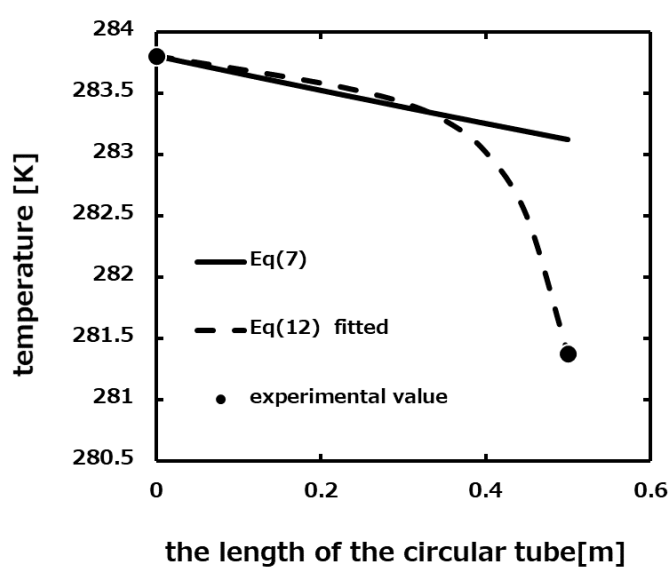

Figure 6. The temperature distribution in the reactor with the nitrogen at atmospheric pressure

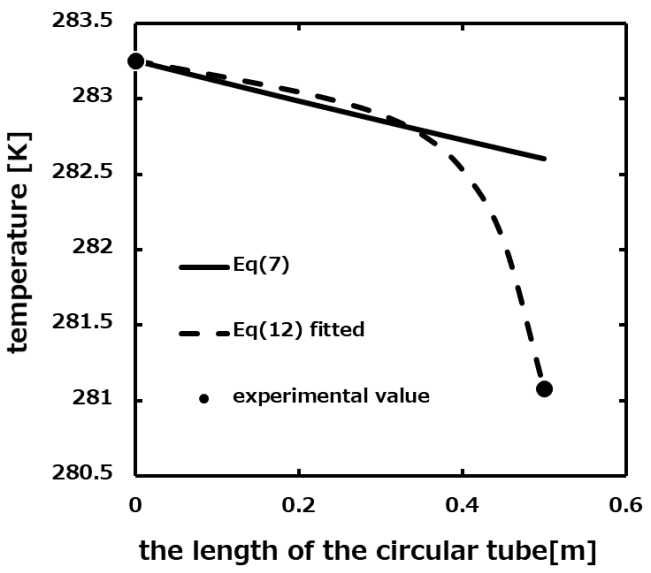

Figure 7. The temperature distribution in the reactor with the HCFC-22 at atmospheric pressure

Figures 6 and 7 show the calculation and experimental results of the temperature distribution in the reactor with $\mathrm{N}_{2}$ and HCFC-22 gases at atmospheric pressure. In this condition, gas hydrate cannot be formed and this is a gas-liquid two-phase case. When there was no back mixing, the temperature was decreased slightly and linearly. The temperature at $Z=0.5$ (gas inlet position) deviated from the experimental temperature. Therefore the model with back mixing for gas-liquid two-phase was tested according to Equation (12). However, the temperature calculated using the axial thermal conductivity $k_{\mathrm{ez}}$ calculated based on literature didn't approach the experimental result. When an axial thermal conductivity was changed to fit the experimental temperature, approximately 15-20 times higher value was obtained. This result implies that the actual mixing is harder than that of the calculated value of the effective axial thermal conductivity. This may be due to the mixing effect of a static mixer. It was suggested that it is 
necessary to reconsider the equation for calculating the effective axial thermal conductivity in the future.

Using the fitted axial thermal conductivity, the temperature distribution at the bottom part $(Z=0.5 \mathrm{~m}-$ $0.35 \mathrm{~m}$ ) changed suddenly. The reason for this may be that the heat transfer by back mixing is larger than by the convective heat transfer. On the other hand, the change in the temperature at the upper part $(Z=0 \mathrm{~m} \sim 0.35 \mathrm{~m})$ was slow. This result suggests that the convective heat transfer is larger than the heat transfer by back mixing in this part.

In the case of pressurized condition (0.3 MPa, 276K), the temperature distribution in the reactor denoted the same tendency of temperature at atmospheric pressure. The back mixing at pressurized condition was harder than that at atmospheric pressure because the number of the effective axial thermal conductivity at pressure is larger than that at atmospheric pressure.

\subsection{The temperature distribution in the reactor with hydrate}

Figure 8 shows the temperature distribution in the reactor with hydrate. Also, in this case, the temperature distribution in the reactor denoted the same tendency of temperature change at various pressure conditions. The analysis result of Equation (11) overlapped with equation (7). This implied that the heat of formation of hydrate has little effect under this experimental condition (0.3 MPa, 278K).

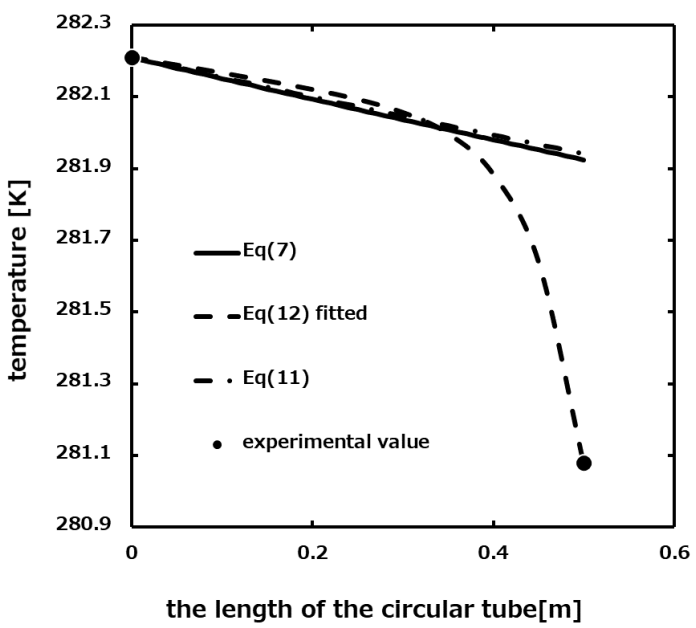

Figure 8. The temperature distribution in the reactor with hydrate

\section{Conclusion}

We calculated the axial temperature distribution of hydrate formation reactor by several heat transfer models step-by-step. By using the temperature in the reactor without the gas, the average velocity of air-cooling and the overall heat transfer coefficient were obtained. The temperature distribution in the gas-liquid two-phase flow was calculated by the heat transfer model proposed. The results implied that the back mixing was harder at pressure than that at atmospheric pressure in this reactor. Further investigation and validation will be carried out for the temperature distribution under hydrate formation conditions.

\section{Acknowledgments}

A part of this research was carried out with the support of JSPS research grant $16 \mathrm{~K} 06821$.

\section{References}

Javanmardi, J., S. Ayatollahi, R. Motealleh, and M. Moshfeghian; "Experimental Measurement and Modeling of R22 $\left(\mathrm{CHClF}_{2}\right)$ Hydrates in Mixtures of Acetone + Water," J. Chem. Eng. Data, 49, 886-889 (2004)

Muroyama, K., K. Hashimoto, T. Kawabata, and M. Shiota; "Axial Liquid Mixing in Three Phase Fluidized Beds," Kagaku Kogaku Ronbunshu 4, 622-628 (1978)

Muroyama, K., M. Fukuma, and A. Yasunishi; "Wall-toBed Heat Transfer Coefficient in Gas-Liquid-Solid Fluidized Beds," Canadian J. Chem. Eng., 62, 199-208 (1984)

Tajima, H., Y. Oota, and K. Yamagiwa; "Improving the Gas Recovery and Separation Efficiency of a HydrateBased Gas Separation," Chem. Eng. Res. Design, 92, 2770-2774 (2014) 